\title{
EL PROYECTO ARQUITECTÓNICO Y LAS FORMAS DE HABITAR: EL CASO DE ESTUDIO DE BUCARAMANGA*
}

Lina María Zuluaga Giraldo**

Universidad de Pamplona, Colombia

Mercedes Fanny Virginia Higuera Peña***

Universidad de Pamplona, Colombia

Ericcson Yahir Hernández ${ }^{* * * *}$

Universidad de Pamplona, Colombia

Recibido: 6 agosto 2013

Aprobado: 23 septiembre 2013
Análisis de crecimiento en la ciudad de Bucaramanga.

Fuente: Ericcson Yahir Hernández, 2013

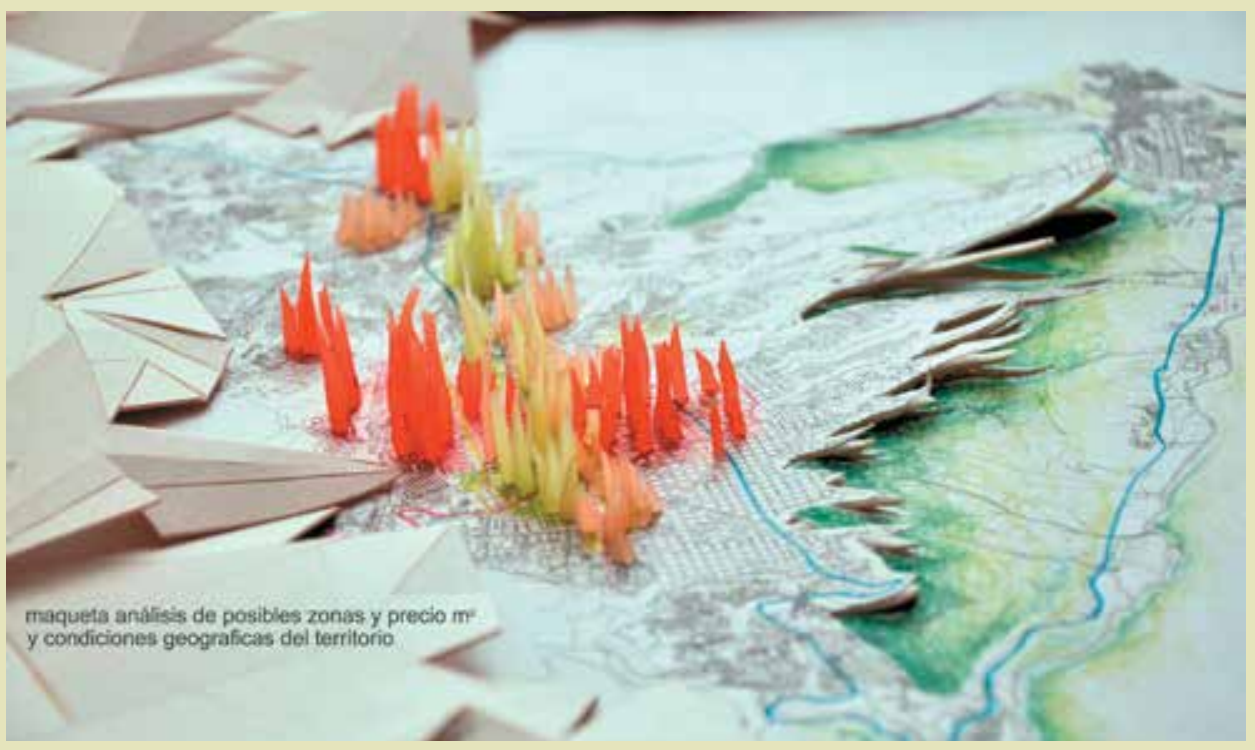

\section{RESUMEN}

Las formas de habitar son estudiadas como elemento básico y determinante en la formulación de estrategias para la propuesta de un proyecto arquitectónico de vivienda que responda a las necesidades de un grupo específico de población estrato medio en la ciudad de Bucaramanga. Es así, como la preocupación por el diseño del espacio doméstico está dada por el habitante como sujeto que realiza la actividad de habitar y no sólo desde tipologías arquitectónicas. El estudio es llevado a cabo con una metodología mixta de corte inductivo, que permite definir las categorías específicas, ejes centrales de la investigación agrupados así: por un lado, la población y los tipos de familias, y por otro, las formas de habitar y los deseos habitacionales. No se puede estandarizar el diseño arquitectónico de la vivienda, ya que no existe una familia tipo con características poblacionales idénticas y, por tanto, se presenta una utilización diferenciada del espacio habitado. Por lo anterior, el espacio debe ser pensado de una manera flexible y adaptable a las necesidades propias de cada grupo familiar.

\section{PALABRAS CLAVE}

Habitar, Espacio Habitado, Espacio Doméstico, Proyecto Arquitectónico. 


\title{
THE ARCHITECTUAL PROJECT AND THE FORMS OF INHABIT AND LIVING FORMS: CASE STUDY IN BUCARAMANGA
}

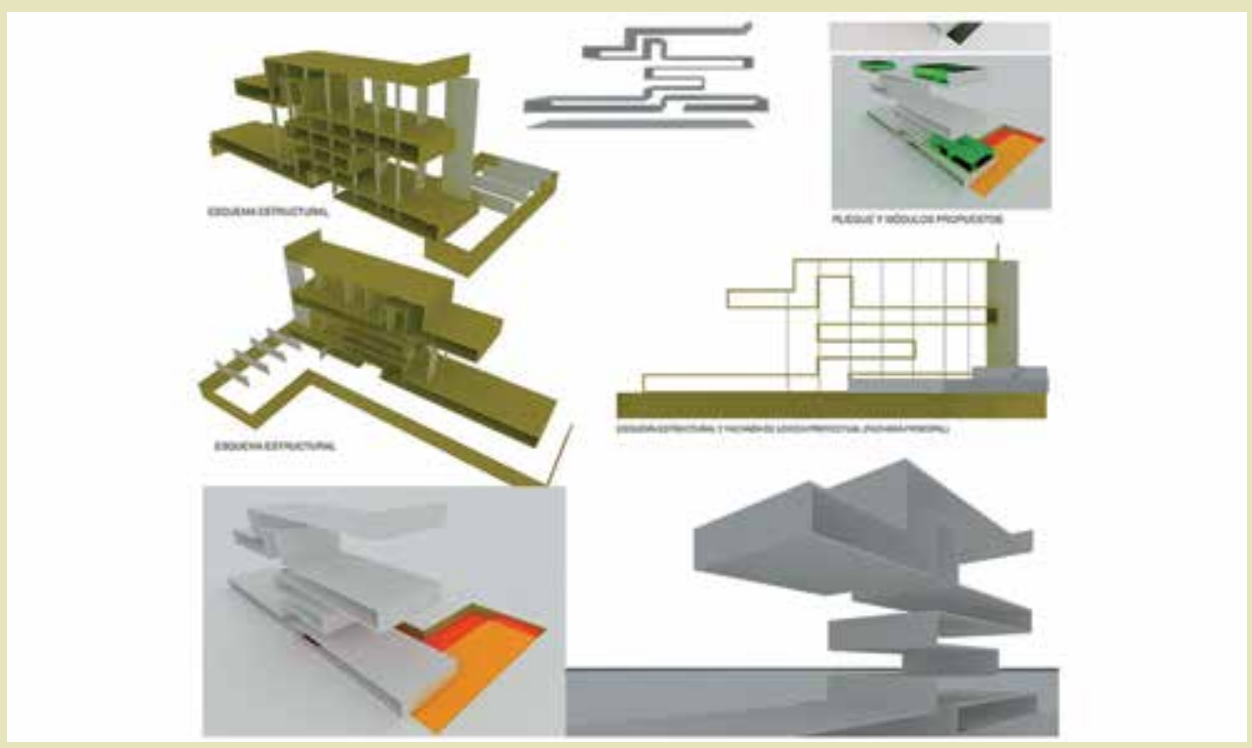

Ciclo de transformación módulo I. Fuente: Ericcson Yahir Hernández, 2013

\begin{abstract}
The forms of inhabit are studied as a basic and determining element in the formulation of strategies for the proposal of an architectural project for dwellings that satisfies the needs of a specific population of median income individuals in the city of Bucaramanga. That way, concern for the design of the domestic space is given by the inhabitant as a resident who carries out the activity of inhabit, and not just by set typologies architectural. The study is conducted with mixed methodologies that allow the definition of specific categories, central to the investigation, grouped in the following ways. On one side the population and types of families, and on the other the forms of inhabit and housing desired. One may not standardize the architectural design of the residence, since a families with identical characteristics do not exist, and utilization of the living space will vary. Because of the reasons outlined above, the living space must be designed in a flexible manner so that it can adapt to the individual needs of each family.
\end{abstract}

\section{KEYWORDS}

Inhabit, Living Space, Domestic Space, Architectural Project. 


\section{INTRODUCCIÓN}

El hombre "habita" en la manera en que "es" en el mundo, y este "habitar" produce diferentes formas de "hábitats". Así pues, las prácticas cotidianas de cada población y sus imaginarios marcan tendencias diferentes respecto a las expectativas espaciales requeridas según sus características.

Como menciona Rapoport el hombre escoge su lugar de habitación según sus deseos: "en realidad, en la mayoría de los casos el hombre escoge y selecciona ambientes, y este proceso de selección del hábitat (observado en todos los seres vivos) constituye el aspecto más importante del efecto producido en las personas por su entorno" (Rapoport, 2003, p.24). Sin embargo, las condiciones del mundo contemporáneo han llevado a confundir el sentido de habitar con el simple problema de ocupar un espacio y con la mera construcción de formas, en muchos casos tan arbitrarias como vacías y carentes de significados (Yori, 2007); y no como el "lugar" de habitación. En algunos casos, los estudios del proyecto arquitectónico han sido abordados más desde categorías propias de su condición de hechos materiales, con un enfoque estético y/o funcional, lo que reduce nuestra disciplina a la proyección de formas, insistiendo sobre cualidades estéticas y propiedades funcionales olvidando el fenómeno mismo de habitar.

En el proyecto arquitectónico debe considerarse también, y como hecho fundamental, el habitar en todas sus dimensiones. Diferentes disciplinas han abordado el tema como la filosofía, la sociología, la antropología, la psicología, entre otras, a partir de que las prácticas en el espacio habitado son prácticas sociales que se insertan en éste dándole significado y en donde interactúan muchas fuerzas que a la vez transforman al habitante. Destacamos aquí a Martín Heiddeger con el "espacio existencial", Otto Friedrich Bollnow y Maurice Merleau-Ponty con el "espacio vivencial", Henri Lefevbre con la "producción social del espacio" Edward Hall Claude Lévi-Strauss y Amos Rapoport con el estudio de las relaciones entre espacio vivido y rasgos y comportamientos de una determinada cultura.

Igualmente, y a partir de las reflexiones de arquitectos, dentro de la historia del siglo $X X$ se han realizado aproximaciones al "habitar" desde el "espaciar". Destacamos a Christopher Alexander (1980) al describir el lenguaje de patrón como un método estructurado que ayuda a comprender y conocer las prácticas de los habitantes sobre el espacio habitado, dando solución a un problema determinado de la arquitectura desde la relación contexto y forma; y a Muntañola Thornberg (2004) al investigar sobre el lugar que habitamos en su doble interacción, el medio que propicia ciertas conductas y el actuar de los habitantes que modela asimismo ese medio.

Entonces, es necesario realizar indagaciones que orienten acciones sobre el hábitat desde las formas mismas del habitar para reconocer fenómenos de valor social y cultural dentro del espacio construido.

\section{METODOLOGÍA}

El estudio se realiza basado en una metodología mixta (cuantitativa-cualitativa) de carácter inductivo, de lo particular hacia lo general, a partir de un estudio de caso. La población escogida pertenece a un grupo estrato medio de una institución pública de la ciudad de Bucaramanga, tomando como muestra del objeto de estudio la mitad más uno de los grupos familiares (26). 
El problema planteado se analiza descomponiendo cada uno de los elementos que intervienen para definir las categorías específicas, ejes centrales de la investigación, agrupadas así: por un lado, la población y los tipos de familias, y por otro, las formas de habitar y los deseos habitacionales. Las características de la población y los tipos de familia son determinados a través de encuestas, mientras que las formas de habitar y los deseos habitacionales se establecen por medio de entrevistas y de observaciones sistemáticas.

La entrevista se estructura teniendo en cuenta los mecanismos de identificación y la relación entre el entorno y los comportamientos de los seres humanos (EBS) propuestos por Rapoport (2003); el entendimiento de los mecanismos que vinculan a su entorno es absolutamente esencial, tanto para la comprensión de los fenómenos, como para la capacidad de modificarlos. Las observaciones son realizadas en el espacio y en el tiempo doméstico habitado, lo que permite de forma sistemática, definir las prácticas y usos sobre dicho espacio e identificar sus significados.

A través de una fundamentación conceptual sobre el habitar y mediante el análisis de los resultados arrojados por los instrumentos mencionados, se proponen las estrategias para el hábitat de la población objeto de estudio.

\section{EL CONCEPTO DE HABITAR DESDE DIFERENTES MIRADAS}

El simple hecho de ser individuos nos identifica directamente con el habitar, entonces, dicho concepto se puede asociar al conjunto de prácticas que resultan de actividades propias del hombre dentro de un entorno específico y que generan algunas necesidades. Es así, como el construir se convierte en la suplencia directa de estas necesidades, "por lo tanto [sic] el construir pertenece al habitar y el habitar crea la necesidad de construir" (Heidegger, 1994).

En este sentido, se considera de gran importancia tener en cuenta diferentes reflexiones que partan del hombre y de sus prácticas, particularmente con relación al habitar doméstico, ya que desde la casa es que generalmente el hombre despliega su ser para encontrar en ésta su esencia, es decir su "ser en el mundo" o "ser ahí" y desde allí lanzar propuestas de diseño (Cuervo, 2009, p.15I).

Sin embargo, la producción de la vivienda durante las primeras décadas del siglo XX llevaron a una masificación de ésta, con el fin de responder a intereses inmobiliarios y suplir la necesidad de gran parte de la población, lo que desembocó en el desarrollo de un programa genérico e indeterminado de necesidades, al ser formulado para una familia estándar (familia-tipo).

Por lo anterior, diferentes ideas han venido desarrollándose desde el surgimiento del movimiento moderno, en busca de dar solución a esta problemática. Por ejemplo, Christopher Alexander (1980) expone su "teoría de los patrones" hacia la década de los setenta, basada en los comportamientos establecidos y asentados culturalmente en las clases medias norteamericanas. Es importante resaltar que en esta década se presentan reacciones contra el universalismo abstracto e indiferenciado de las respuestas arquitectónicas que no atendían los cuestionamientos del usuario y del lugar (Sarquis, 20I I, p. 14), como es el caso del Team X.

Es entonces en el movimiento moderno donde se dan importantes reacciones frente a la estandarización con propuestas fundamentadas en conceptos como flexibilidad, versatilidad, apropiación, adaptación, personalización, entre otros. Mies Van der Rohe se pronunciaba en 1927: "Hoy, el factor de la economía hace que la racionalización y la estandarización sean imperativas. Por otra parte, la creciente complejidad de nuestros requerimientos exige 
flexibilidad". También, destacamos la casa Schroeder de Rietveld (1926) al poner de manifiesto en ésta la flexibilidad. Otros ejemplos son: Hertzberger con el espacio polivalente, Habraken en una alternativa para el alojamiento de masas, Tuner desde la vivienda y todo el poder para los usuarios, Rapoport al incorporar la cultura en la arquitectura, entre otros.

Siguiendo con la preocupación que el movimiento moderno emprende por el espacio habitado y que en la actualidad continúa, Christian Norberg-Shultz (2005) seguidor de Heidegger propone:

Para ayudar al hombre a sentirse a gusto en un mundo nuevo. Y ese estar a gusto, lograr ese "bienestar", [sic] no es solo tener cobijo, ropa, alimentos, sino que significa además y sobre todo identificarse con un entorno físico y social, implicando una sensación de pertenencia y participación, la posesión de un mundo conocido y comprendido. La pérdida definitiva de esas características, que se mencionan aquí como un "sentirse a gusto", un "bienestar", pero arquitectónicamente fundamentadas en valores mucho más esenciales como identificación, sensaciones, pertenencia y participación, es un escenario que arriesga cada vez en un mayor número de situaciones, en este siglo $\mathrm{XXI}$, una descontextualización de la arquitectura (p.17).

De esta manera, se retoma el "espacio habitado", aquel que es vivido por un hombre, o una sociedad específica con prácticas determinadas culturalmente, en contra del positivismo que conformaban algunas construcciones modernas y que Aldo Van Eick fundamentará mediante una tarea interdisciplinaria con la antropología y la filosofía.

Los seres humanos por sus modos de habitar siempre están buscando un lugar central, el cual va a ser siempre su casa. La casa se convierte, por tanto, en el "espacio habitado" fundamental y dentro de ésta el hombre organiza un lugar que lo haga sentir cómodo, por tal motivo, este espacio deja de ser algo geométrico y abstracto y pasa a convertirse en el "espacio habitado", en el "espacio vivencial". Lo anterior, nos conduce a afirmar que para el hombre la casa es el lugar de identidad más claro y es en ésta donde da cuenta de sus expresiones y representaciones del mundo en el que es y está.

Porque la casa es nuestro rincón del mundo. Es — se ha dicho con frecuencia [sic] nuestro primer universo. Es realmente un cosmos. Un cosmos en toda la acepción del término. Vista íntimamente, la vivienda más humilde ino es la más bella? Los escritores de la "habitación humilde" evocan a menudo ese elemento de la poética del espacio. Pero dicha evocación peca de sucinta. Como tienen poco que describir en la humilde vivienda, no permanecen mucho en ella. Caracterizan la habitación humilde en su actualidad, sin vivir realmente su calidad primitiva, calidad que pertenece a todos, ricos o pobres, si aceptan soñar (Bachelard, 1975, p.28).

En la actualidad, muchos arquitectos también han retomado el habitar como condición fundamental para generar el espacio arquitectónico, entendiéndolo como el "espacio habitado" y mucho más cuando se trata del espacio doméstico. Ejemplo de ello son: Ravetllat cuando retoma los modos de vida para el proyecto, Ábalos y Herreros al tener en cuenta que las transformaciones más importantes en la vivienda están sistemáticamente dirigidas a aumentar la complejidad técnica y la versatilidad del ámbito privado y que se debe buscar aumentar en el interior la indeterminación de los espacios, pero al mismo tiempo la capacidad de fragmentación y el aislamiento de éstos (Kuri, 20I I). 
Los distintos aportes y reflexiones frente al tema del habitar dan a entender que éste como tal, está acompañado de diversos acontecimientos, hechos, experiencias, modos de vida, deseos, significados del hombre y sus relaciones con el entorno físico y simbólico construido.

\section{EL FENÓMENO DE LA ESTANDARIZACIÓN EN LA CIUDAD DE BUCARAMANGA}

El capitalismo introdujo en la vivienda su transformación, pasando de valor de uso a valor de cambio y poco a poco dentro del desarrollo urbano acaecido durante el transcurso del siglo XX, la vivienda pasó de ser el lugar de "enraizamiento" que propone Bollnow (1969, p. I2I) a convertirse en una mercancía. Este proceso de mercantilización se puede considerar el gran cambio material que afectó la vivienda, y en general toda la arquitectura del siglo XX. La masificación y estandarización de la arquitectura doméstica se afianza con el acelerado crecimiento metropolitano.

Bucaramanga fue una de las ciudades colombianas en donde se presentó dicha condición después de la segunda mitad del siglo pasado, y sobre todo durante las décadas de los setenta y ochenta, lo que sumado a la falta de suelo para su expansión, se vio reflejado una mercantilización masiva de viviendas en altura, es decir, apartamentos. El apartamento que no es diseñado para nadie en particular, como sí lo es la vivienda lujosa o la de los más pobres, se caracteriza por la desaparición del sentido de lugar, de significado y permite que se transfiera como cualquier producto mercantil. Se puede entonces aludir, de acuerdo a lo propuesto por Yori (2007) a la "desobjetualización" de la vivienda, en donde sólo cabe una relación de comercio mercantil entre el hombre y "los objetos” (p.48), en este caso la casa.

El crecimiento de los sectores céntricos de Bucaramanga y la concentración de los servicios, demandaron (fruto de las leyes del mercado del suelo) el aumento del costo de la tierra. Esto se convirtió en una determinante para el aprovechamiento máximo del suelo y se refleja en una masiva reproducción tipológica de vivienda apilada. Así pues, la ciudad empieza a tener un desarrollo en vertical y se populariza el apartamento (ver Figuras I y 2 ).

Asimismo, el desarrollo tecnológico y el aumento del costo de los suelos centrales, llevaron a la compactación de las áreas de estos apartamentos, que gracias a las transformaciones culturales del siglo $X X$ en el desarrollo de la vida doméstica, permitieron hacer deseable espacios pequeños e integrados. Ejemplo de ello, es la desaparición de límites formales: cocina-comedor, cocina-patio de ropas, cocina-sala, sala-comedor, cocina-sala-comedor; estos espacios se convierten en ámbitos únicos y sus usos diferenciados se dan en gran medida por el mobiliario.

Igualmente, a finales del siglo XX algunas de las características mencionadas cambiaron en la producción de los apartamentos en la ciudad de Bucaramanga y empezó a aparecer el Loft, producto de los procesos que se habían venido presentando en la disolución de los lugares de la vivienda, de los cambios de la estructura familiar, de las nuevas tecnologías domésticas (micro-ondas, lavadora, secadora, entre otros) y de los procesos de comercialización.

Se presentan entonces dos tendencias dentro del mercado inmobiliario de apartamentos de la ciudad. La primera es la desarrollada a partir de la década de los ochenta que se mantiene hasta la actualidad y es el apartamento convencional, una forma común y masiva de desarrollar la vivienda, donde la secuencia de usos se presenta así: acceso, cocina, estar, comedor, dormitorios, servicio; esta organización no sólo no se adapta a las transformaciones de los últimos años en los modos de vida familiares, sino que además, por 
Figura I. Análisis crecimiento de Bucaramanga Fuente: Ericcson Yahir Hernández (20|3). Basado en: DANE, P.O.T., Bucaramanga.

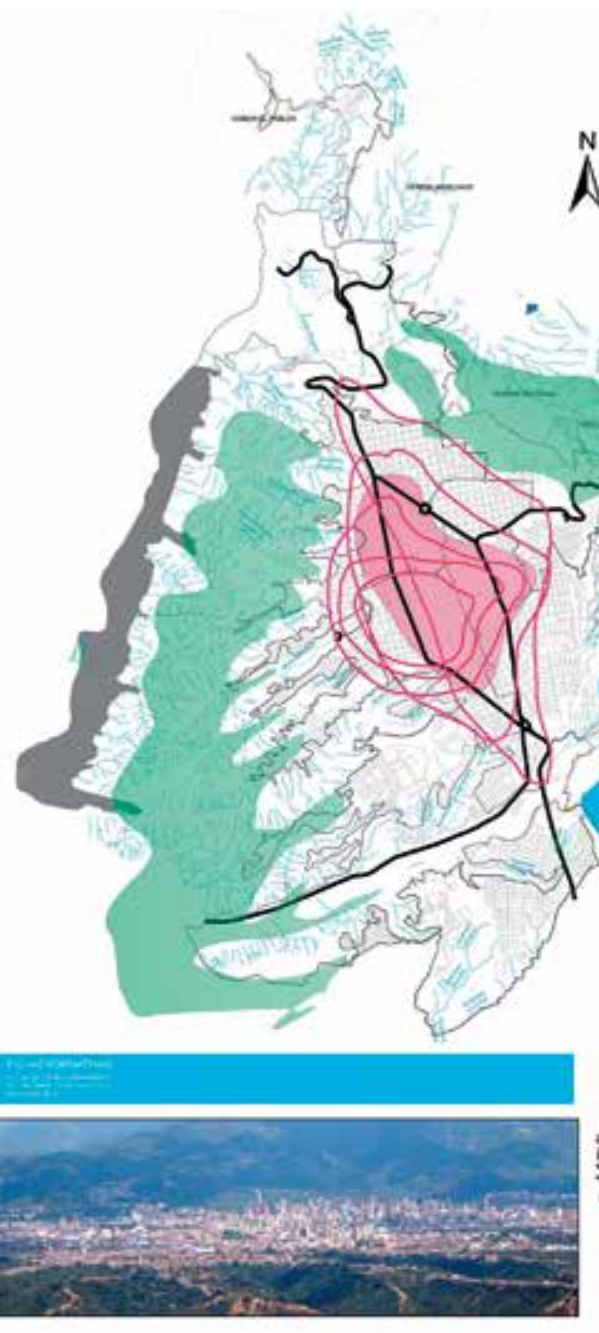

$N$

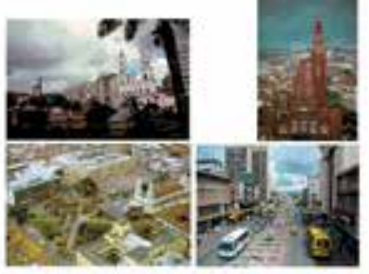

CRECIMIENTO BUCARAMANGA
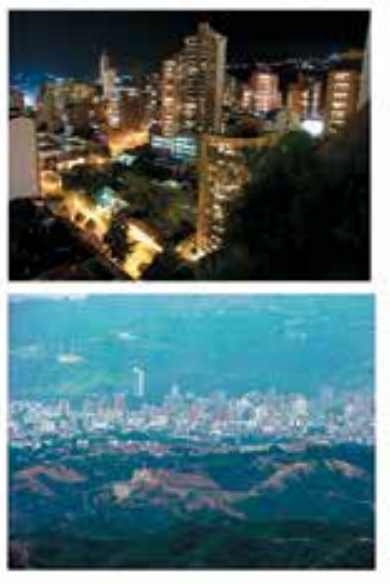

EVOLUCIÓN DE LA VTVIENDA EN ALTURA

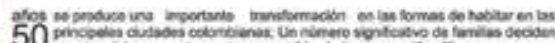
70

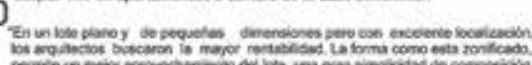

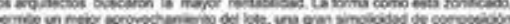

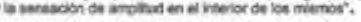

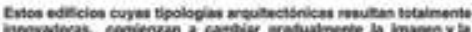

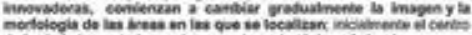

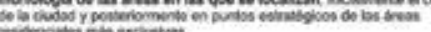
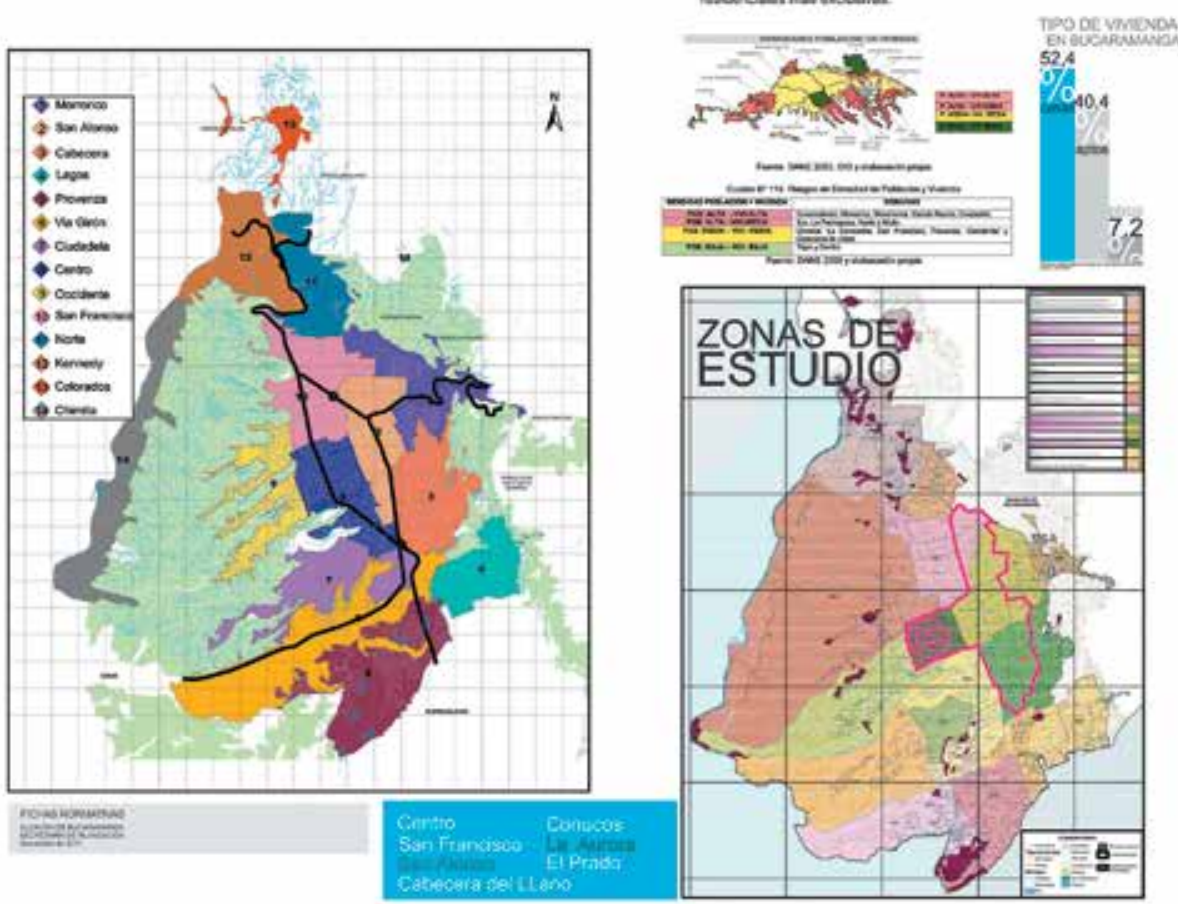


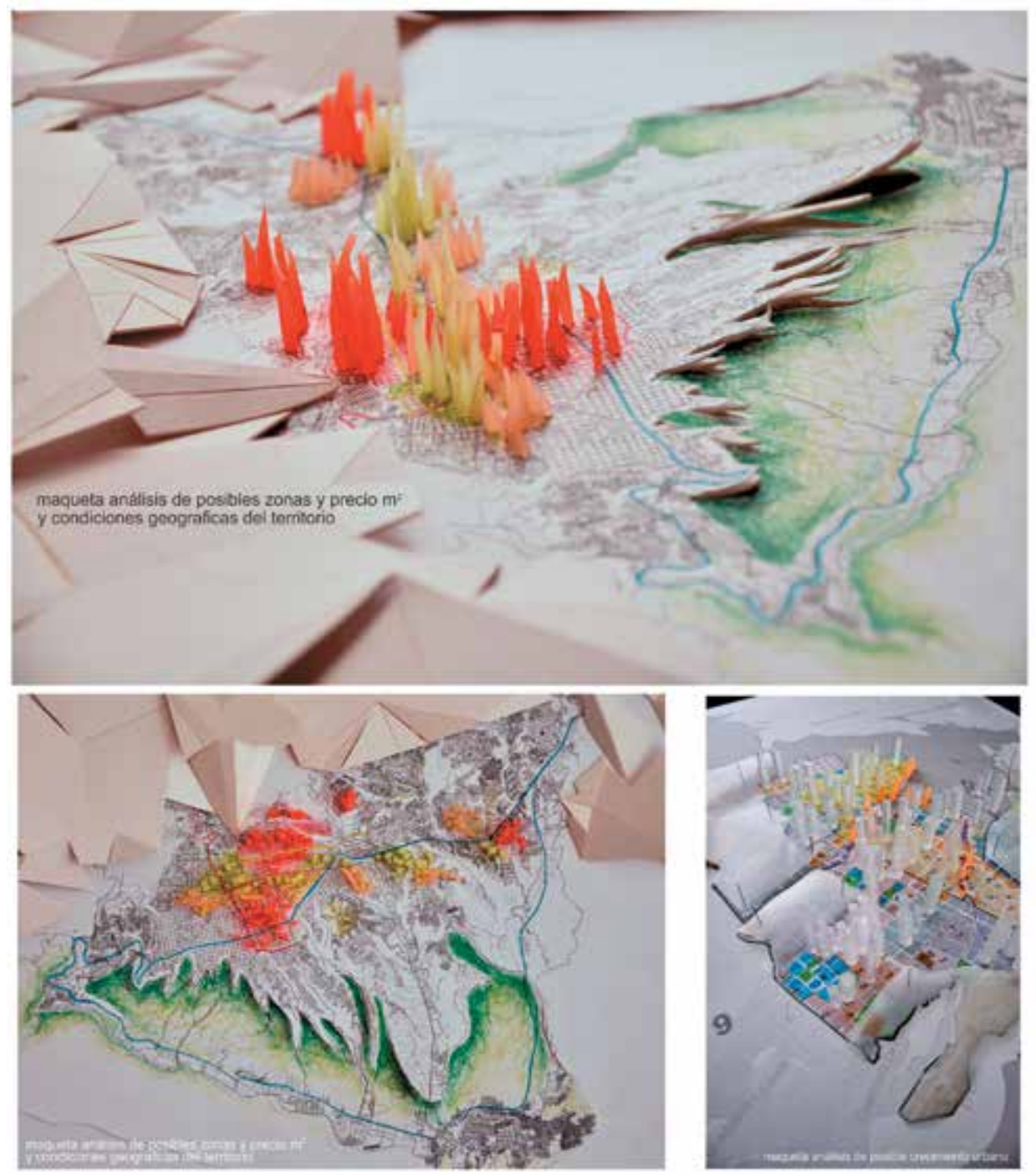

Figura 2. Crecimiento en altura de

Bucaramanga y aspectos geomorfológicos Fuente: Ericcson Yahir Hernández (2013). Basado en: P.O.T. Bucaramanga.

sus sistemas constructivos, no presentan ningún tipo de flexibilidad debido a la dificultad para generar modificaciones del espacio, además de convertirse en una oferta de planta para familias tipo.

La segunda como el Loft, desarrollada en las últimas décadas y en muchísima menor proporción, permite valorar otras alternativas funcionales posibilitadoras de condiciones de uso más flexibles y adaptables a las trasformaciones del espacio doméstico habitado, lo que representa un potencial debido al abanico de posibilidades por las múltiples opciones que podría presentar el espacio habitado, respondiendo, de este modo, a las formas de habitar.

De esta forma, y ante la necesidad del máximo aprovechamiento del suelo urbano en la ciudad, la tipología edificatoria de apilamientos seguirá siendo una alternativa para solucionar una de las necesidades básicas de los ciudadanos, como es la vivienda. Sin embargo, es necesario el desarrollo de estrategias proyectuales y alternativas tipológicas que se constituyan en respuestas a los requerimientos de las formas de habitar, debido a las constantes $y$ aceleradas transformaciones sociales, familiares y culturales. 


\section{RESULTADOS}

\section{La Población y los tipos de familia}

- El mayor porcentaje de la población se encuentra concentrada en adultos entre 30 y 40 años y niños menores de 10 años.

- Con respecto a las actividades desarrolladas por los integrantes de las familias, el porcentaje más alto se encuentra en el trabajo dependiente y formal de adultos y jóvenes y en el estudio de básica primaria de niños menores de 10 años.

- El nivel de ingresos familiares es variado, se mantiene en un rango de 3 SMLV hasta 9 SMLV, que en promedio corresponde a 6SMLV.

- De acuerdo a los ingresos económicos de las familias, la población estudiada pertenece al estrato medio, lo que conlleva a considerar que dicho grupo poblacional no tiene la posibilidad de adquirir una vivienda por encargo único, pero sí tiene la opción de comprar una vivienda comercial.

- Conforme a los rangos de ingresos familiares y al costo de vivienda en la ciudad de Bucaramanga, la población objeto de estudio tiene la posibilidad de acceder a viviendas entre $60 \mathrm{~m}^{2}$ y $120 \mathrm{~m}^{2}$.

- Se encontraron diferentes tipos de familias, que definidos por Sarquis (20I I, p.26) serían: familia nuclear (padres e hijos) la que presenta el mayor porcentaje; familia ampliada (base nuclear y pariente cercano viviendo con ellos); familia ensamblada (matrimonios o separaciones de uno o de ambos padres, con hijos propios y compartidos); familia monoparental (mamá e hijo); jóvenes viviendo juntos; ancianos viviendo juntos y personas viviendo solas. Por lo anterior, no se puede hablar de una familia-tipo, ni de un programa de necesidades genérico e indeterminado (ver Figura 3).

Figura 3. Tipos de familias encontrados Fuente: Ericcson Yahir Hernández (2013).

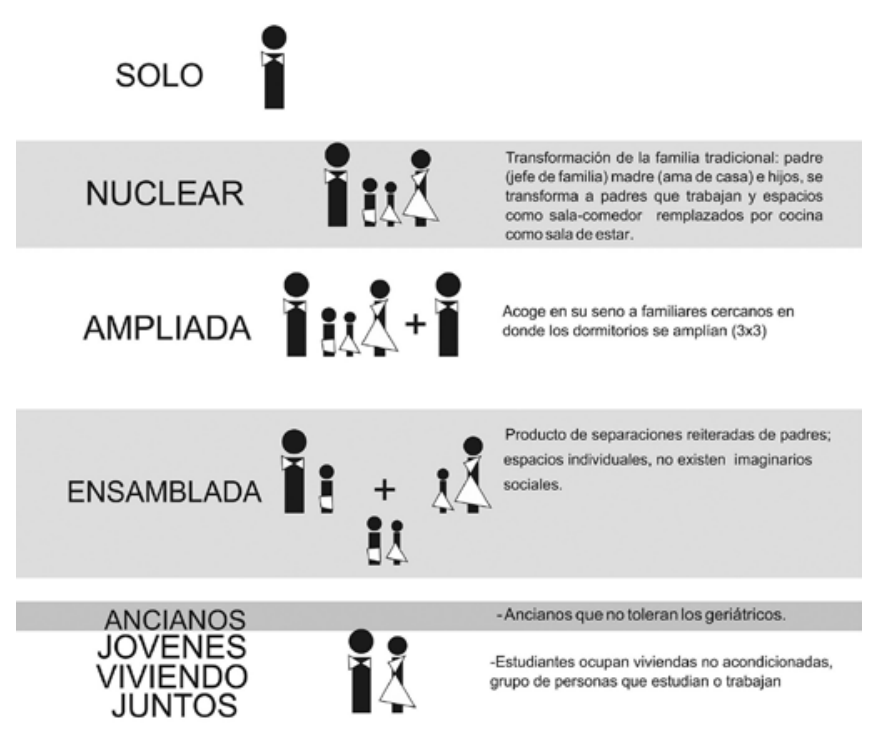

De la misma manera, el espacio puede cambiar con el transcurrir del tiempo, porque las prácticas, las necesidades, el número de integrantes de la familia puede variar en el. 


\section{Las formas de habitar y los deseos habitacionales}

- El lugar dentro del Área Metropolitana deseado por la población objeto de estudio y específicamente ubicado en la Meseta de Bucaramanga es el Barrio la Aurora; por su proximidad con el sitio de trabajo, las facilidades de conexión, movilidad y la cercanía a centros equipados de la ciudad (ver Figura 4).

- Los espacios domésticos de la población objeto de estudio, conservan la tripartición clásica: "social - privado - servicios". Sin embargo, a partir de las observaciones de las prácticas sobre estos espacios, se pudo determinar el uso polivalente de muchos de los lugares de la casa. La cocina no sólo es el espacio para la preparación de alimentos, sino además el espacio para comer; los dormitorios no son sólo el espacio de intimidad y descanso, sino además, el espacio de estudio, de trabajo, de ver la televisión y el lugar donde se recibe a los amigos íntimos; el comedor no sólo es el espacio para comer sino también es usado como espacio de trabajo y estudio.

- Corredores y halls se observan como lugares indefinidos que se interpretan como espacios de relación para usos no previstos a priori, debido a la ocupación espontánea por parte de niños, adultos, ancianos y algún tipo de mobiliario, que hacen de estos espacios un lugar intermedio entre las prácticas privadas y sociales en el interior de la casa, lo que implica una voluntad de cambio en las formas de habitar acordes con las formas de pensar, porque el área libre y de circulación dan a los usuarios la opción de vincular un uso concreto a éstas, ya sea como área de juego, de descanso, de estudio, entre otras.

- El televisor ubicado en una sala de estar ha sido sustituido por las pantallas de los computadores y los teléfonos personales que se ubican en cada dormitorio de la vivienda, de esta manera, el internet permite la conexión individual y directa con el mundo exterior, que antes se daba por medio del televisor, la radio y el teléfono fijo. Igualmente, estas prácticas individualizadas generan un ajuste en las relaciones del grupo, lo que hace que cada integrante de la familia no esté con los demás y necesite espacios de aislamiento; así pues, el pequeño estar común y la sala tienden a convertirse en espacios sub-utilizados. A la vez, empieza a desaparecer la estructura autoritaria de la familia tipo instaurada durante la modernidad, para generarse una cohabitación de miembros basada en relaciones de respeto.

- A pesar de que las prácticas individualizadas tienden a ser un común denominador, el espacio de la sala sigue siendo el protagonista de la casa por su dimensión, su ubicación jerárquica, su situación con respecto a la fachada, su mobiliario y su decoración. Sigue primando el carácter representativo de dicho espacio.

- El deseo en gran parte de las familias entrevistadas es el cuarto de baño amplio, luminoso y con la implementación de aparatos no tradicionales, lo que demuestra el interés por convertir este lugar en un espacio de placer y no en un espacio puramente funcional ligado únicamente al aseo.

- En la mayoría de las unidades de vivienda observadas, el cuarto de ropas por sus tamaños tan reducidos no cuentan con mobiliario adecuado y eficiente, por tanto, no permite que todas las funciones allí practicadas (depósito de ropas sucias, lavado, secado, planchado y almacenado) se puedan llevar a cabo de forma cómoda y en muchos casos, se fragmenta en diversos espacios de la casa, especialmente en las alcobas en donde se desarrolla el planchado y el depósito de ropas sucias.

M 109 REVISTA M VOL. 10 No.2. JULIO-DICIEMBRE 2013 • FACULTAD DE ARQUITECTURA • UNIVERSIDAD SANTO TOMÁs COLOMBIA 
Figura 4. Análisis del sector y lote. Ubicación

territorio

Fuente: Google Earth y Ericcson Yahir Hernández,

2013.

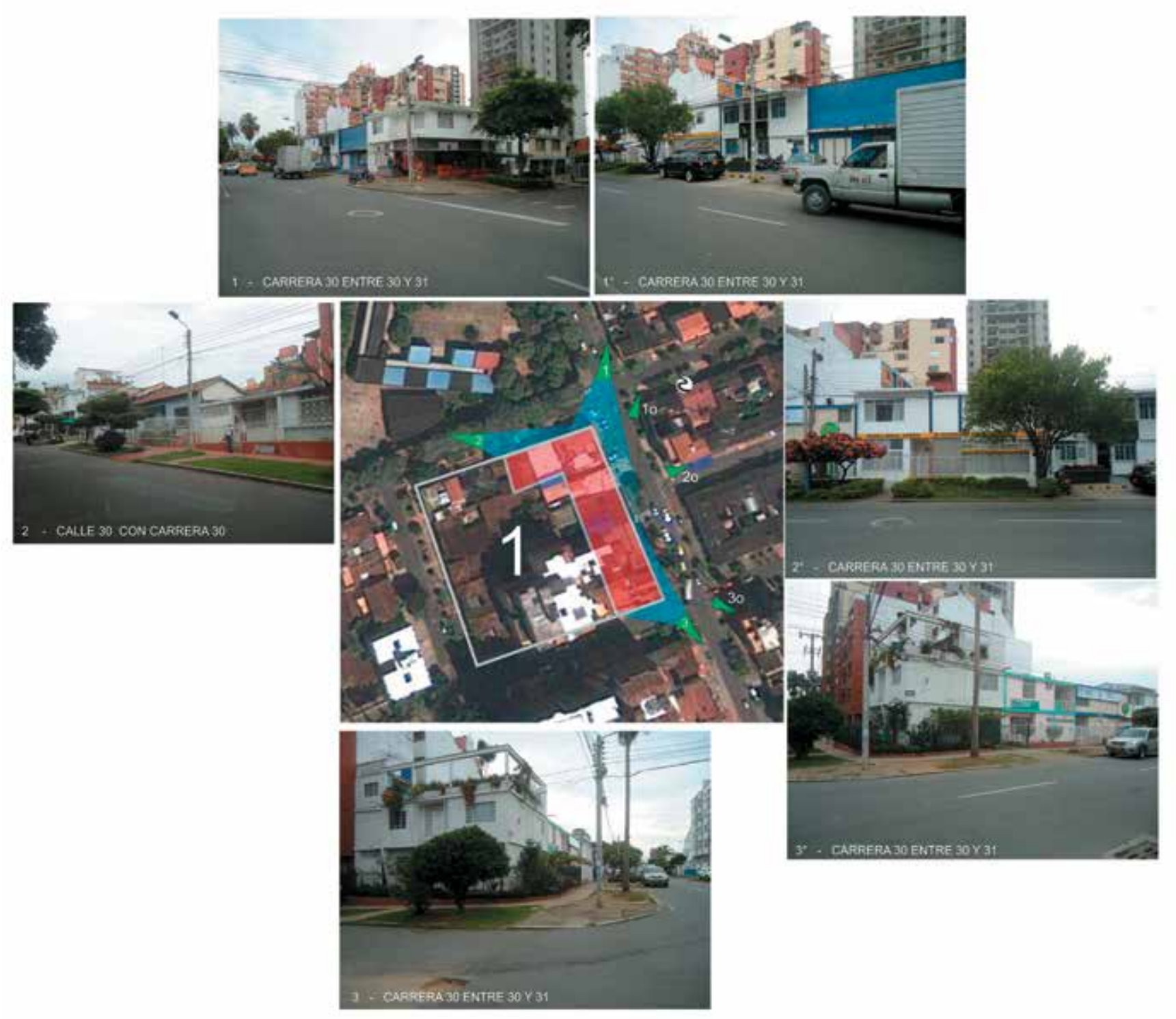




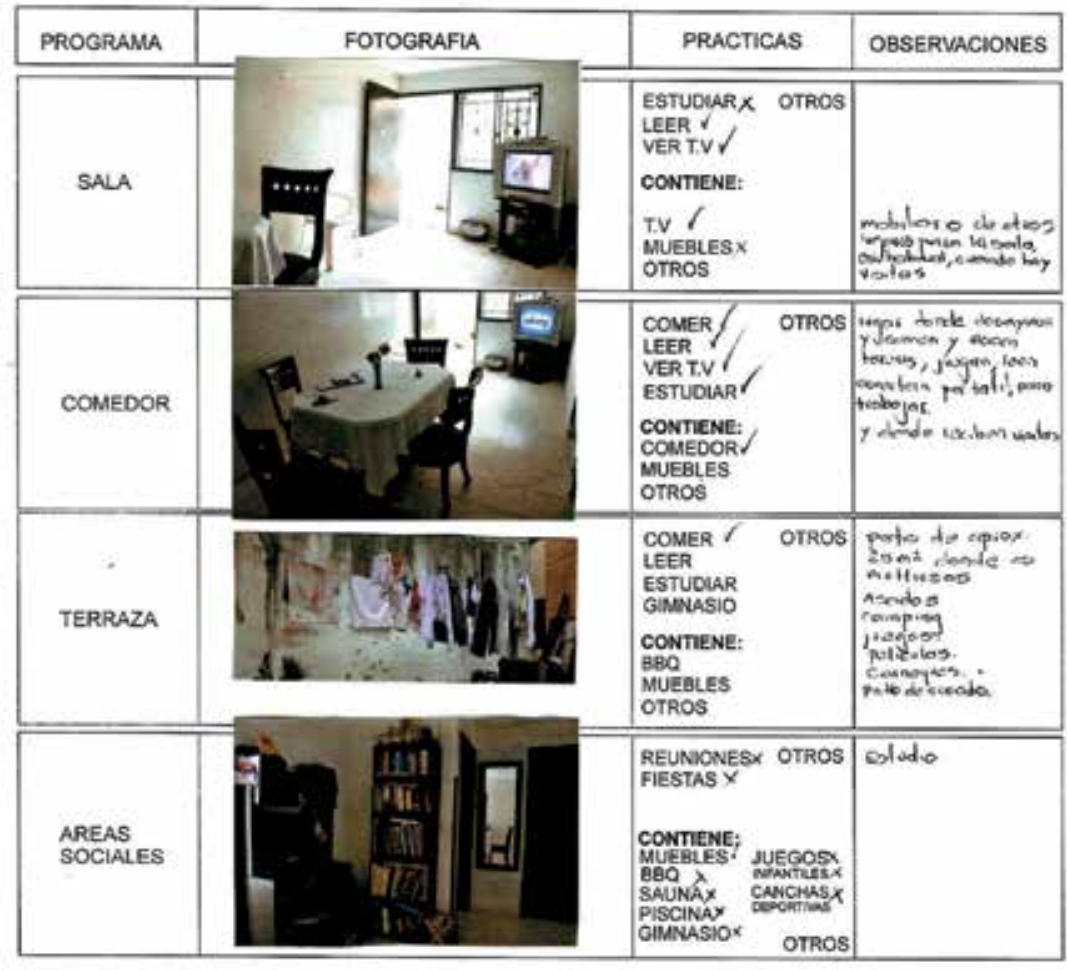

CONCLUSIONES

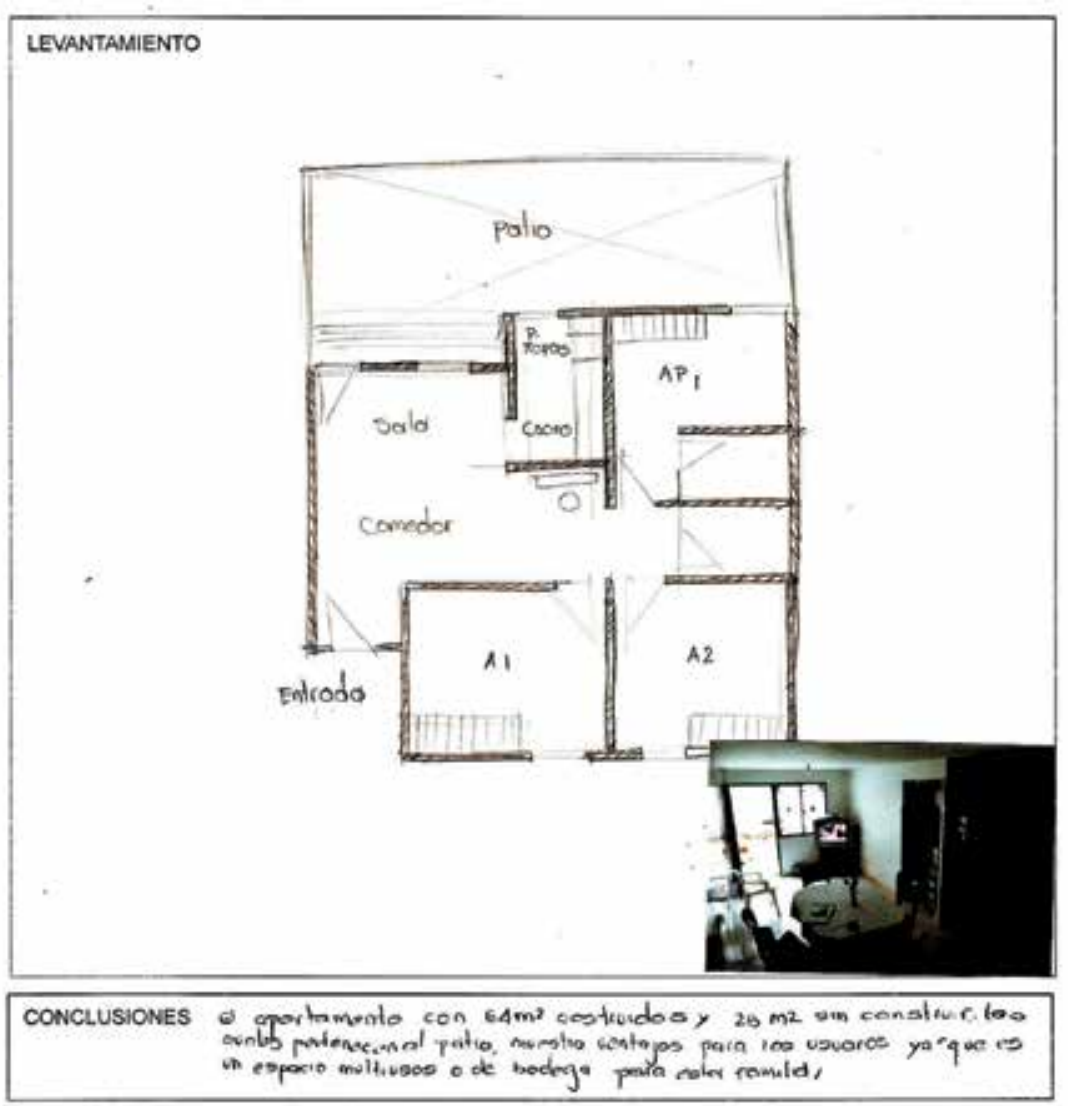

Figura 5. Observaciones sistemáticas Fuente: Ericcson Yahir Hernández (2013)
Figura 6. Levantamiento de vivienda Fuente: Ericcson Yahir Hernández (20।3) 

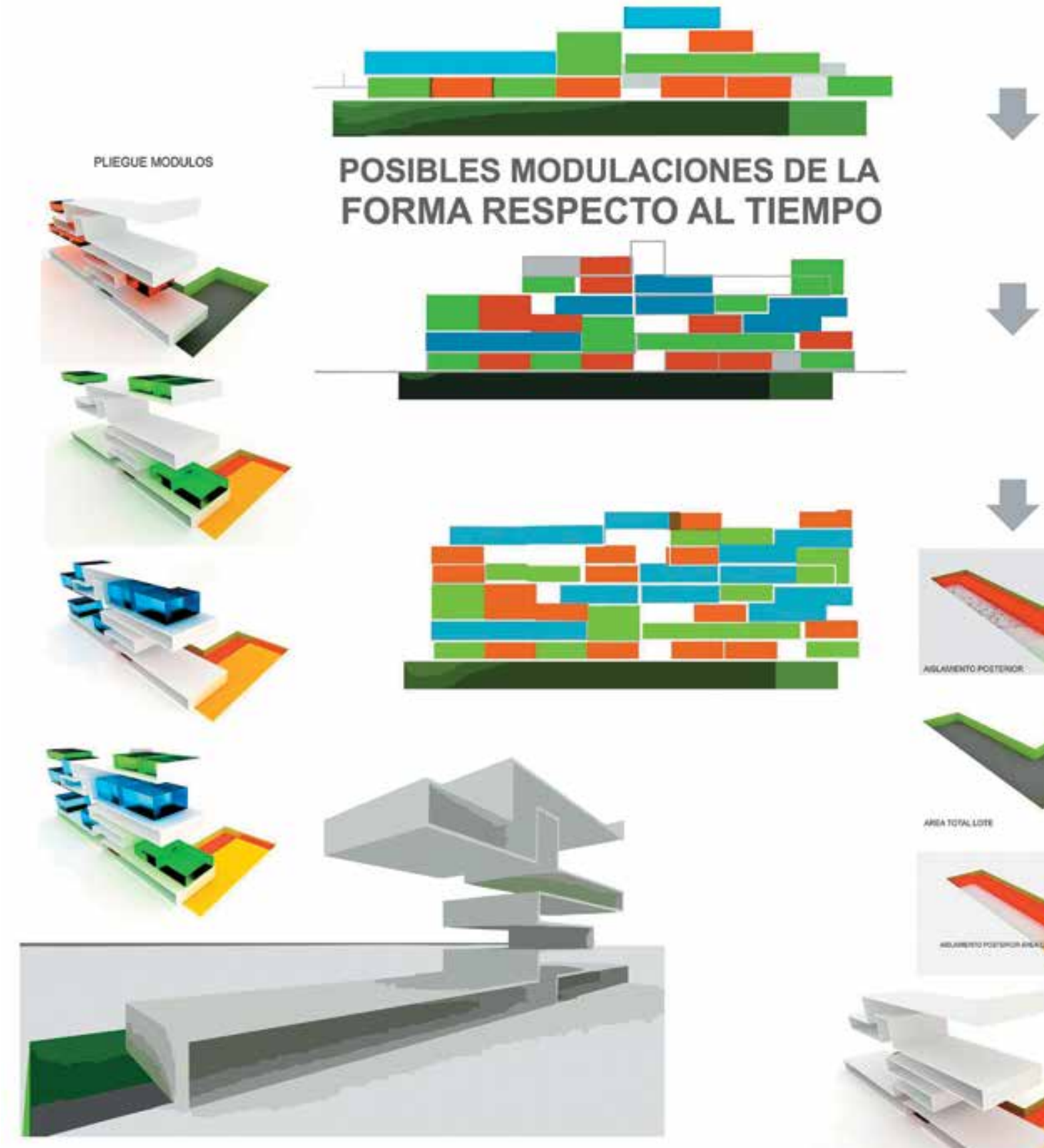

POSIBLES MODULACIONES DE LA FORMA RESPECTO AL TIEMPO
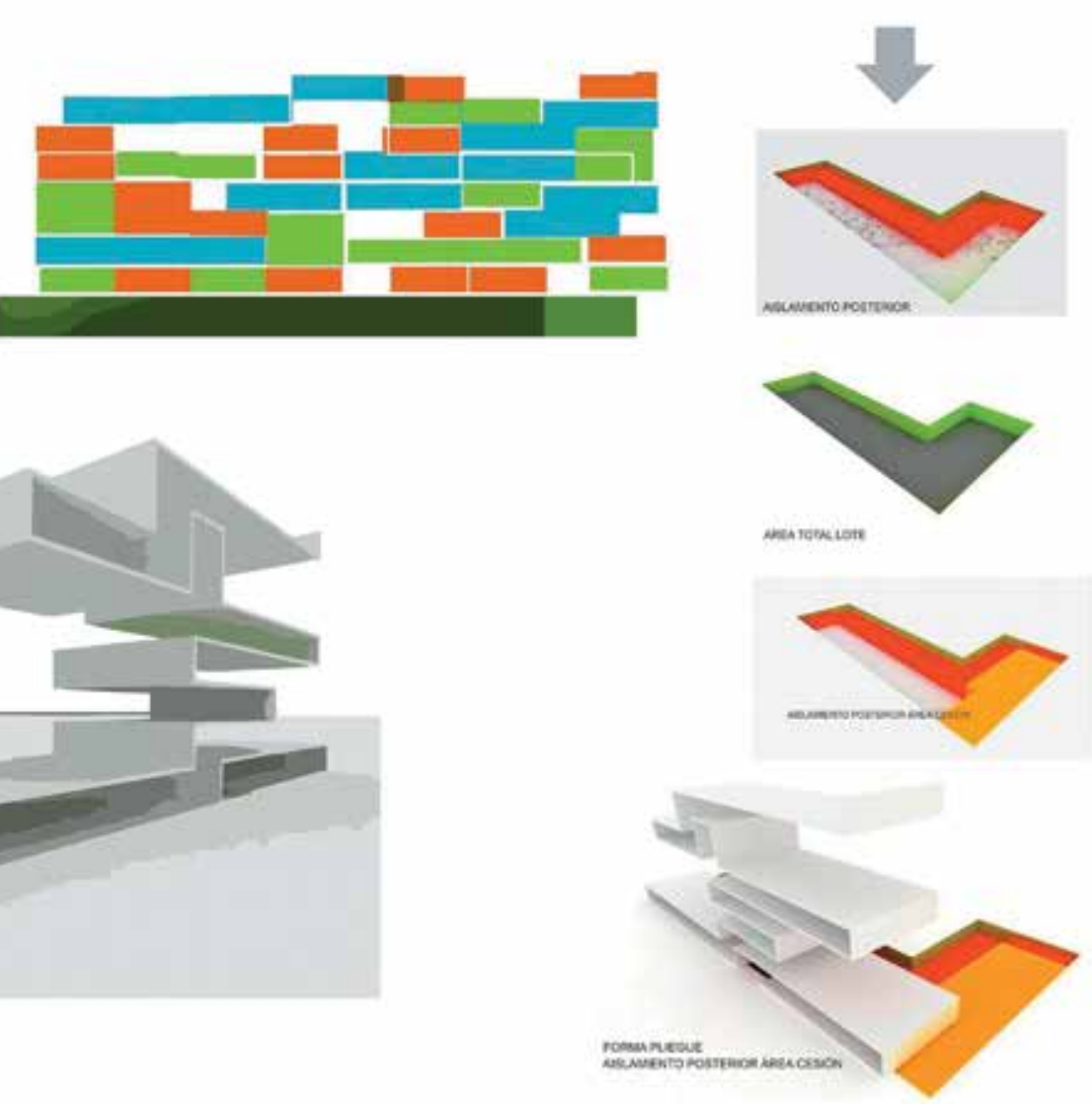


\section{PLIEGUE (MODULAR)}

El sistema que tiene las mismas cualidades del proyecto de vivienda en altura FLEXIBILIDAD, ADAPTABILIDAD YVERSATILIDAD.

hace parte del fundamento estructural ya que se adapta a las formas modulares de diseño, que con el transcurso del tiempo y a medida que la agrupacion de vivienda siga creciendo puede ir evolucionando., sin perder identidad e ir cambiando de forma sin perder la logica proyectual.

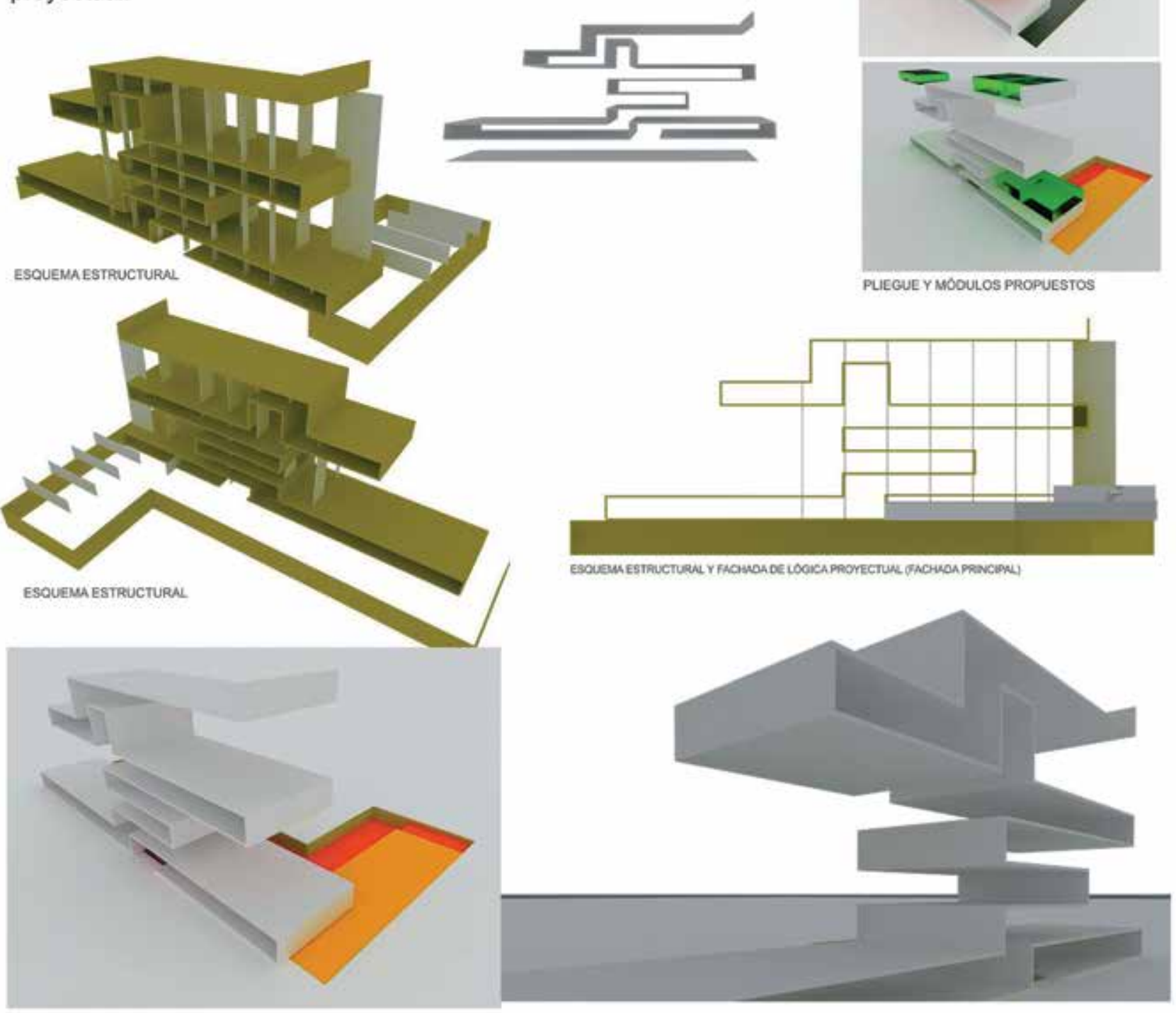


Figura 9. Ciclo de transformación módulo I en

el transcurrir de los años

Fuente: Ericcson Yahir Henández, 2013.

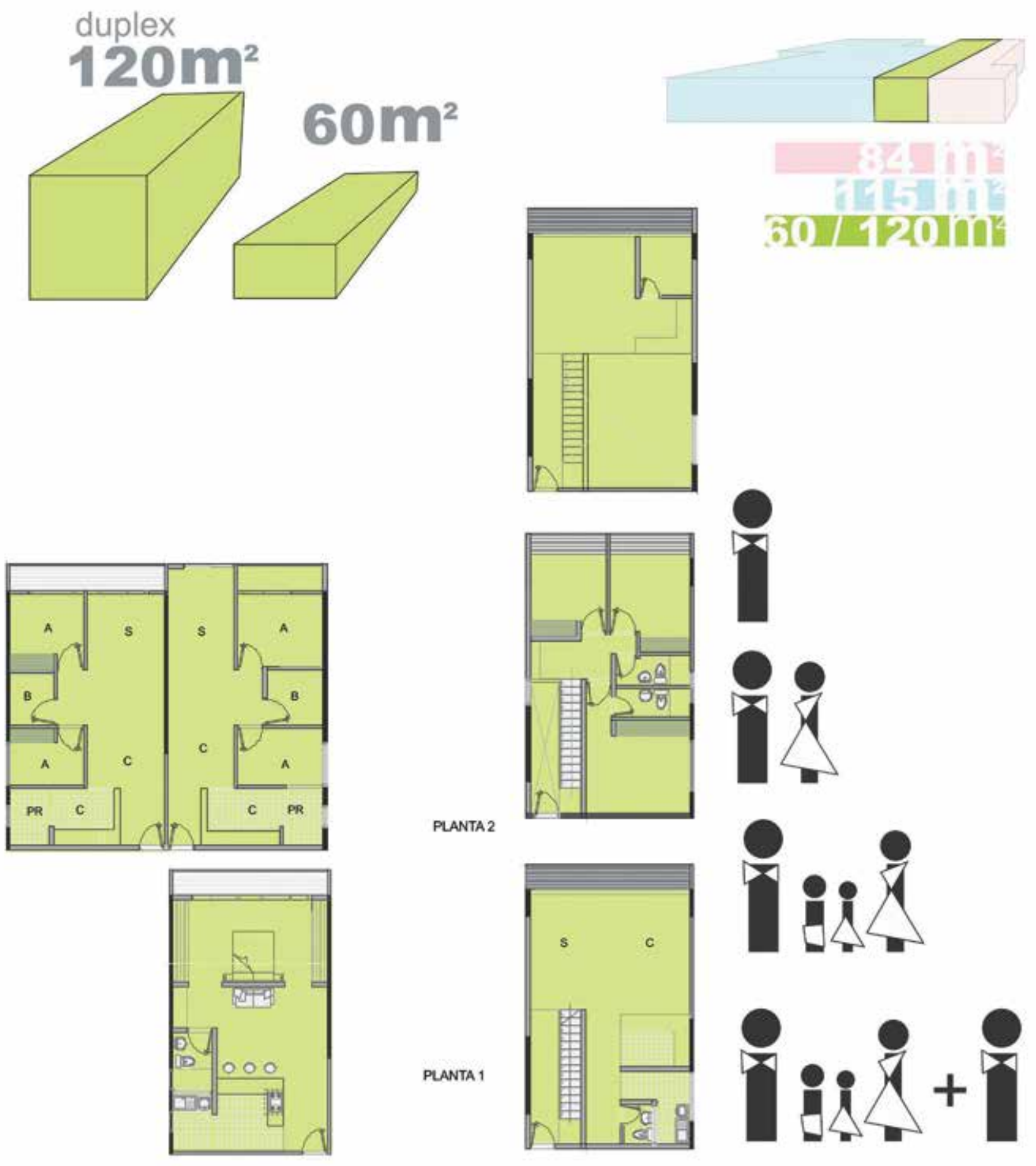


Figura 10. Ciclo de transformación módulo 2

$115 \mathrm{~m}^{2}$

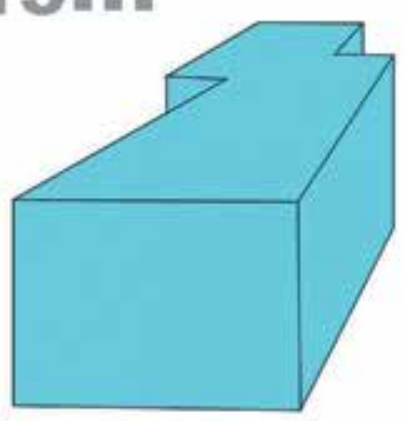

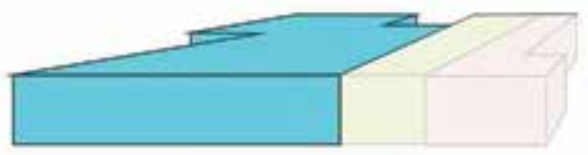

iftoliti
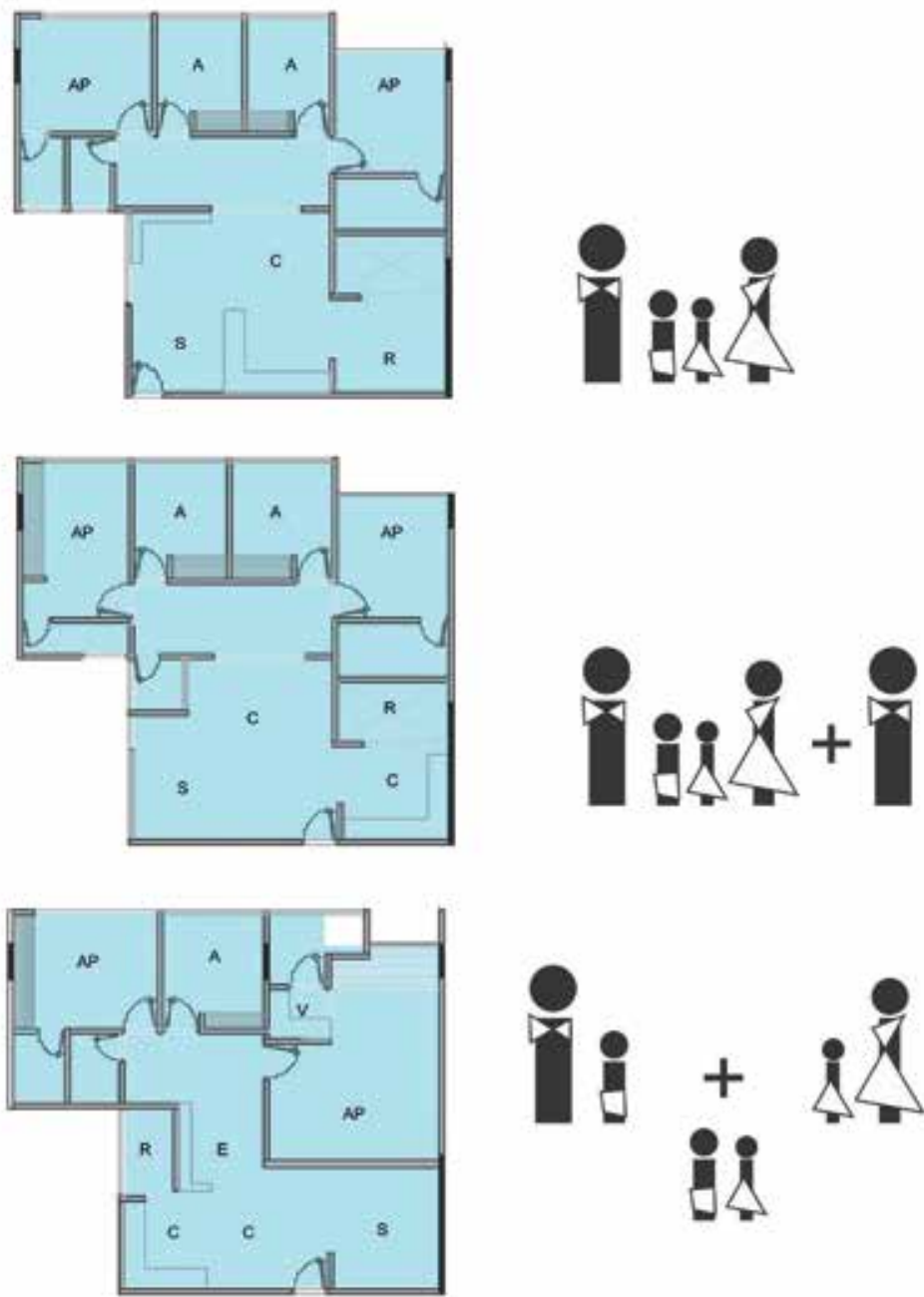
Figura II. Ciclo de transformación diaria,

módulo I (opción I)

Fuente: Ericcson Yahir Henández, 2013.
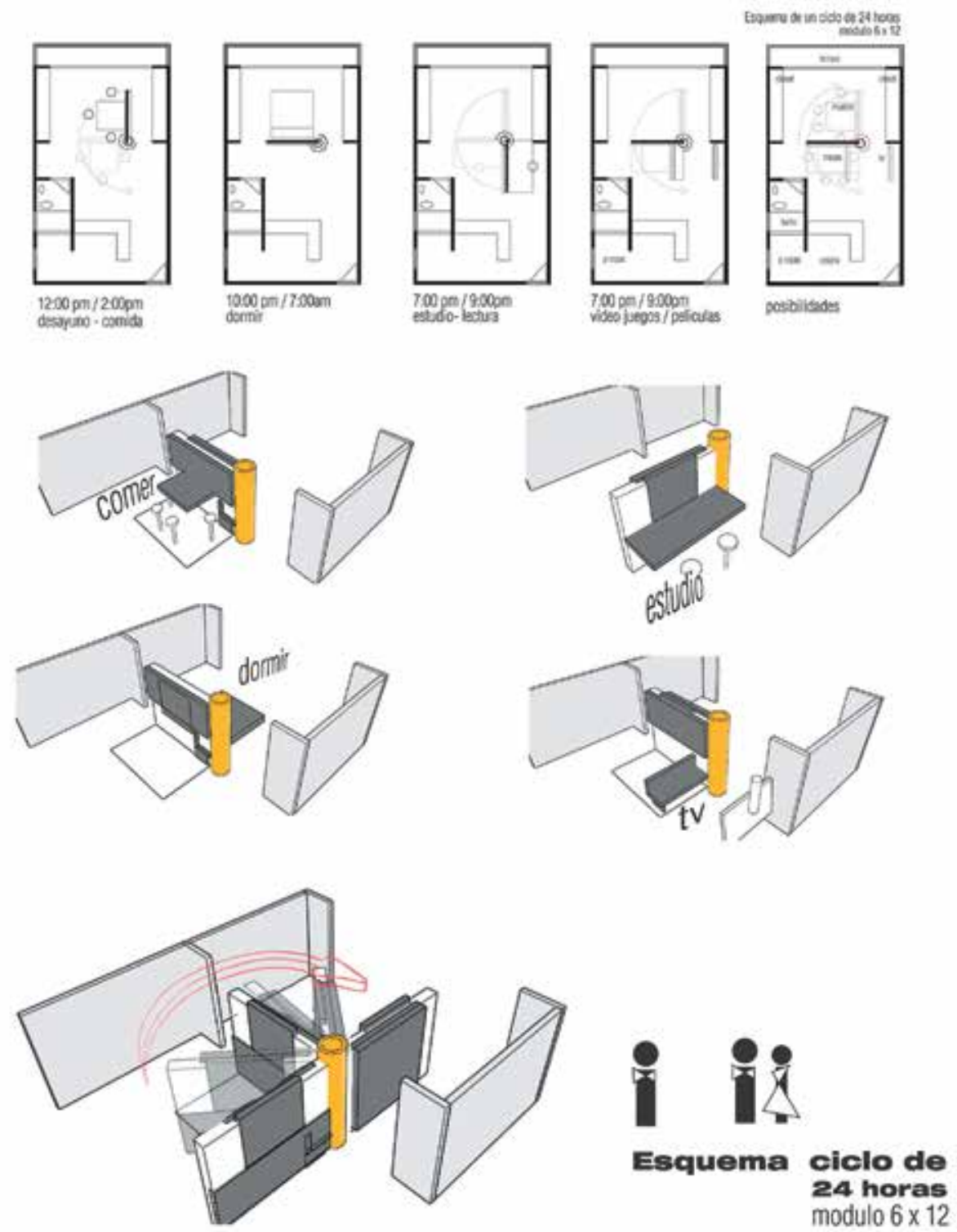
- La cocina como espacio protagonista de las transformaciones acaecidas durante el siglo XX en la casa, pues la tecnología entró al hogar por pequeños electrodomésticos destinados a realizar actividades culinarias, se convierte en las unidades habitacionales observadas en un espacio donde se desarrollan diversas prácticas en el conjunto familiar, como el cocinar juntos o con amigos, comer, ver televisión y escuchar música; lo que hace que cada vez más, dicho espacio esté integrado al resto de la casa y se dé valor a un mobiliario de cocina perceptible desde zonas comunes de la vivienda.

- En la mayoría de casos, las familias prefieren un diseño personalizado para su casa que corresponda con sus formas de habitar; lo que hace pensar en un diseño adaptable y flexible según las necesidades de cada usuario.

\section{CONCLUSIÓN: LA PROPUESTA}

La propuesta es abordada a partir de la organización del espacio, tiempo y significado, que se expresan físicamente desde los postulados de Rapoport (2003) como paisaje cultural, y que para el caso específico, será el paisaje de la vivienda, compuesto por un sistema de lugares dentro de los que discurren un sistema de actividades (descansar, cocinar, trabajar, estudiar, recrearse, asearse, entre otras); este sistema de actividades está compuesto por elementos fijos y semifijos que serán habitados y recreados por componentes no fijos.

La propuesta va mucho más allá del puro concepto del espacio, dentro de ésta se introduce el concepto del tiempo, debido a que las personas habitan en el tiempo y en el espacio; porque las actividades humanas al igual que las configuraciones sociales y familiares están organizadas en el tiempo. Por lo anterior, el tiempo se convierte en un factor importante al momento de la proyectación, en palabras de Juhani Pallasmaa:

Tenemos una necesidad mental de caer en la cuenta de estar enraizados en la continuidad del tiempo, $y$ en el mundo artificial es cometido de la arquitectura facilitar esta experiencia. La arquitectura doméstica el espacio ilimitado nos permite habitarlo, pero éste debería así mismo domesticar el espacio infinito y permitirnos habitar el continuum del tiempo (Pallasmaa, 2006, p.32).

Son introducidos los conceptos de Versatilidad, Flexibilidad y Adaptabilidad, como estrategias que responden a las continuas transformaciones familiares, sociales y culturales que permiten la modificación del espacio sin perder la identidad:

- La generación de elementos fijos y semifijos en el espacio construido permiten adaptabilidad a distintos programas y requerimientos: la cercanía de cocina y cuarto de baño posibilita que cualquier lugar pueda adoptar distintos usos.

- Condiciones de movilidad en componentes internos (muros, muebles, entre otros) permiten modificaciones espaciales y dimensionales a través de fragmentaciones 0 unificaciones, de adaptaciones en el mobiliario diario que permitan transformaciones del espacio de acuerdo con las prácticas cotidianas, de intercambiabilidad de usos o alternancia de programas de uso.

- Incorporación de una estructura de soporte topológica - constructiva que aunque fija permite la versatilidad y facilita la transformación del espacio habitado. 
- La flexibilidad como estrategia que permite personalizar y hacer propio el espacio habitado, conduce además, a la participación de los individuos en la construcción de su lugar de habitación.

- La introducción de un componente lúdico ante la posibilidad de transformación y renovación continua del espacio habitado.

Generalmente los seres humanos buscan un lugar central, que de acuerdo con Bollnow (1969) les genere "enraizamiento" y que pueda convertirse en su lugar de habitación, en su "espacio existencial", por lo tanto, este espacio deja de ser algo geométrico y abstracto y pasa hacer el espacio vivenciado, es decir, adquiere cualidades sentimentales humanas. Es por esta razón, que es importante introducir dentro del espacio doméstico el concepto de significado, no solamente como un añadido a la función, sino como el aspecto más importante de ésta y elemento crucial de los deseos, estimaciones, preferencias y prácticas en el espacio habitado. De esta manera, se responde a las formas de habitar permitiendo que el domicilio, tal como lo plantea Pallasmaa (2006) "pase a integrarse a su identidad" (p.7I) y desde una visión Heideggeriana pase a convertirse en parte de su ser.

\section{REFERENCIAS}

Alexander, C. (1980). Lenguaje de Patrones. Barcelona: Editorial Gustavo Gili.

Bachelard, G. (1975). La poética del espacio (Trad. Ernestina de Champourain). México: Editorial Fondo de Cultura Económica.

Bollnow, O. F. (1969). Hombre y espacio (Trad. Jaime Lopera y de Asiaing). Barcelona: Editorial Labor.

Cuervo, J. (2009). Habitar y diseñar. El diseño como base hacia una teoría de habitar. En: KEPES, 6 (5), I79-190. Medellín: Universidad Pontificia Bolivariana. 
Hall, E. (1982). El lenguaje silencioso. Buenos Aires: Nueva Visión.

Heidegger, M. (1994). Construir, habitar, pensar (Trad. Eustaquio Barjau), en Conferencias y artículos. Barcelona.

Kuri, R. (20I I). La vivienda urbana agrupada. Ante los nuevos cambios culturales: estrategias proyectuales, en Arquitectura y modos de habitar. Bogotá: Ediciones de la U.

Lévi-Strauss, C. (1970). Tristes trópicos. Buenos Aires: Eudeba.

Merleau-Ponty, M. (1975). Fenomenología de la percepción. Barcelona: Editorial Península.

Muntañola T., J. (2004). La Arquitectura como lugar. Barcelona: Universitat Politécnica de Catalunya.

Norberg-Shultz, C. (2005). Principios de la Arquitectura moderna. Sobre la nueva tradición del siglo XX. Barcelona: Editorial Reverté.

Pallasmaa, J. (2006). Los ojos de la piel. Primera edición. Barcelona: Editorial Gustavo Gili.

Rapoport, A. (2003). Cultura, Arquitectura y Diseño. Primera edición. Barcelona: Ediciones UPC.

Sarquis, J. (Compilador). (20I I). Arquitectura y modos de habitar. Bogotá: Ediciones de la U.

Van der Rohe, M. (1927). Sobre mi bloque de viviendas, en Bau und Wohnung. Stuttgart.

Yori, C. M. (2007). Topofilia o la dimensión poética del habitar. Primera edición. Bogotá: Editorial Pontificia Universidad Javeriana. 